\title{
In the Field
}

\section{Arrangement and Description of Architectural Material: My Co-Op Experience at Western Archives}

\section{Introduction}

My primary task as a co-op student at Western University Archives was to arrange and describe (A and D) the architectural output of London architect Charles H. Gillin. A prominent mid-century modern architect, Gillin worked on projects in and around London from the late 1940 s to the late 1970 s. In this commentary, I will outline the process of $A$ and $D$ with respect to architectural material in an attempt to shed light on inherent challenges, while also demonstrating opportunities for facilitating access to this dynamic and informative primary source.

\section{Arrangement}

In 2013, Western acquired approximately 2,300 sets of architectural drawings from Museum London. In amongst this material were hundreds of drawings related to over 75 projects created by Gillin, both in his capacity as an architect for a large engineering firm and as a private contractor. My first task was to arrange these drawings for preservation. This task involved grouping the drawings into projects (which in archival terms became individual series), placing each set of drawings flat in acid-free folders measuring three feet by four feet, and re-shelving each folder in an empty map cabinet with enough space in between them to avoid over-crowding. The challenge was to ensure that data indicating separate projects, such as job numbers and dates, were recorded accurately so that drawings were grouped in the correct series. Another factor 
that complicated my handling of the material was the size and condition of the drawings. On average, the drawings measured approximately 65 by 95 centimeters, and most had at one time been rolled for storage.

\section{Description}

To best serve researchers, the description of architectural drawings should ideally be completed at the item level. Each individual drawing must be closely analyzed so that the relevant data fields can be entered into the archival database. While working in archives, I have learned that there is no "typical" piece of archival material. Each record carries its own set of inherent nuances and contextual baggage that must be considered in order to achieve effective description, and architectural drawings are no different. In a single drawing I might find data such as scale, dates, geographical information (addresses or surrounding areas), names of pertinent individuals (architects or engineers), names of companies involved in the projects, project or job numbers, names of clients, and information about the involvement of various utilities (heating, electrical, air conditioning, etc.). Added to this is the more typical archival work of determining the measurements of each sheet of drawings, the condition of each sheet, and the physical material used in the creation of each drawing (onion skin, paper, blueprint, etc.). Of course, not every drawing would provide each of these data points, but it takes a considerable amount of detective work to ensure that each sheet of drawings has its story told in a way that will best serve researchers. After populating the appropriate data fields, I drafted concise yet informative scope and content notes as a way to advertise what each series of drawings contained, much akin to the descriptions on the back of a novel. 


\section{Reflection}

I came into this position not knowing an exterior elevation from a ground floor ventilating layout, but through a sort of immersion therapy, I now feel that I understand the basics of architectural draftsmanship, or at least enough to help a researcher filter through archival architectural material. This seems to be a recurring theme with archival work: the sheer variety of archival records offer countless opportunities for continual learning, which I find incredibly exciting. Through archival work, you can become very wellinformed and enthusiastic about an aspect of human activity that you never knew you would find interesting.

I enjoy each and every element of archival work (or at least those elements I have experienced thus far!), from interacting with enthusiastic and knowledgeable staff and faculty to the quiet, contemplative work of $A$ and $D$. What I find most attractive however, is playing some small role in the process of making information related to Canada's cultural identity accessible to interested parties, be they academic researchers or members of the public with a passion for history. I am keen to build a career as an archivist due in no small part to my experience at Western University Archives and the people that make it such an exciting and culturally vital institution.

\section{Richard Gale}

Gale, R. (2018). Arrangement and description of architectural material: my co-op experience at Western Archives. Emerging Library \& Information Perspectives, 1 , 120-122. https://doi.org.10.5206/elip.v111.48 